\title{
GENETIC ANALYSIS AND CHARACTER ASSOCIATION IN JAMIR (Citrus jambhiri) ACCESSIONS OF BANGLADESH BY USING MORPHOLOGICAL TRAITS
}

\author{
S. Akhter, M. J. Ferdous, M. R. Hossain ${ }^{1}$ and G. Rabbani \\ Department of Horticulture, Bangladesh Agricultural University \\ Mymensingh-2202, Bangladesh
}

\begin{abstract}
An experiment was carried out to study the morphological variability, characters association, correlation and path coefficient analysis of 14 Jamir accessions during the period from January 2007 to March 2008. Significant variations were observed for all the plant characters studied. The accession CJ09 was characterized with the maximum plant height $(6.20 \mathrm{~m})$, spreading of branch (north-south $4.90 \mathrm{~m}$ and east-west $4.87 \mathrm{~m})$, base girth $(58 \mathrm{~cm})$, plant growth $\left(102.76 \mathrm{~m}^{3}\right)$, tree volume $\left(24.64 \mathrm{~m}^{3}\right)$ and segment length $(9.70)$. The accession CJ15 showed maximum spine length $(25.33 \mathrm{~mm})$, CJ05 was characterized with high lamina area $\left(14.94 \mathrm{~cm}^{3}\right)$. The accession $\mathrm{CJ} 12$ showed the highest \% fruit set $(36.67 \%)$. The highest fruit weight $(1753.33 \mathrm{~g})$, fruit diameter $(46 \mathrm{~cm})$, rind thickness $(2.73 \mathrm{~cm})$ was observed in CJ11. The accession CJ09 was characterized with maximum number of segment (15.33) and pulp weight (746.67). Maximum TSS $(12.20 \%)$ was found in CJ12. The accession CJ09 was characterized with minimum number of seeds (14). Correlation coefficient study indicated that fruit diameter, rind thickness, length of segment and number of segment had positive and highly significant phenotypic association with fruit weight and also genotypic positive association. Percent Fruit set had negative genotypic and phenotypic association with fruit weight. In respect of path analysis, fruit diameter, rind thickness, number of segment, length of segment contributed to maximum phenotypic and genotypic direct effects on fruit weight indicating their importance as selection parameters.
\end{abstract}

Key words : Jamir, Character association, Morphology, Correlation, Path analysis

\section{INTRODUCTION}

Jamir (Citrus jambhiri), belongs to the family Rutaceae, and is popularly known as rough lemon throughout the world. Presumably it is native to northeastern India, where it still grows wild. The rough lemon seems to have been taken to southeast Africa by the

\footnotetext{
1Department of Genetics and Plant Breeding, Bangladesh Agricultural University, Mymensingh-2202, Bangladesh

Correspondence E-mail :- rashedagbau@gmail.com
} 
Portuguese toward the end of the fifteenth or early sixteenth century and then to Europe. It is widely grown in most areas of tropical, sub tropical and border line of sub tropical or temperate regions (Lee and Leader, 2004). Jamir is very important in respect of its nutritional values especially being very rich in Vitamin C. In Bangladesh, mean intake of Vitamin C is far below from the recommended dietary allowance (Ahmed et al., 1998; Nielsen, 2000; Hels et al., 2003; Khan and Ahmed, 2005) and 93\% people are suffering from deficiency of Vitamin C. Jamir can be eaten fresh, which can solve this Vitamin C deficiency partially. It also contains some organic compounds, which work against asthma, antidepressant, stress relief, aids digestion, colds, flue, fever, nosebleeds, mouth ulcers, throat infection and boils. Various kinds of food items like Jam, Jelly, pickle and salad can also be prepared from it.

Annual citrus production of the world (from 1992 to 2002) grew at a rate of $2.3 \%$ and the growth is projected to be continued at a rate of 1.1\% annually up to 2010 (Spreen, 2001; FAO, 2003a and 2003b). Jamir grows everywhere in Bangladesh, but it stands a very low position in respect of production as well as yield. This is particularly due to lack of good quality and high yielding variety. In fact, until now there is no standard or recommended variety of Jamir in Bangladesh. However, there are many landraces in our country, which are resistant against diseases, pests and adverse climatic conditions. So the identification and characterization of all germplasm available is of paramount importance. Correlations in combination with the path coefficient analysis can quantify the direct and indirect contribution of one character upon another (Dewey and Lu, 1989). Specific knowledge on genetic relatedness, the genetics of important traits and their relative association will help to undertake appropriate breeding approach for the improvement of this fruit. Moreover, characterization of our valuable landraces will help in protecting them from piracy by international companies or other countries and will establish our right on them. Keeping these points in mind, this study was framed and materialized with the objective to assess the interrelationship between yield and yield contributing characters of 14 Jamir accessions and to study the direct and indirect effects of important characters on yield.

\section{MATERIALS AND METHODS}

The experiment was conducted at the Jamir orchard (situated between 24\%75" N latitude and $90^{\circ} 50^{\prime \prime} \mathrm{E}$ longitude at the elevation of $18 \mathrm{~m}$ above the sea level) of CVFB (Collection, Molecular Characterization and Conservation of Landraces and Wild Relatives of Different Vegetables and Fruits of Bangladesh) project, Department of Horticulture, Bangladesh Agricultural University, Mymensingh during the period of March 2007 - June 2008. The experiment was laid out in completely randomized block design with three replications. Each of 14 accessions represented one treatment and one plant in an accession represented one replication. The experimental area was under sub-tropical climatic zone and characterized by high temperature and heavy rainfall during April to September and scanty rainfall associated with moderately low temperature during the rest of the year. The soil of the experimental site was silty loam in texture belonging to the Old Brahmaputra Flood Plain. The selected plot was well drained and medium high land having $\mathrm{pH}$ value 8.5 . 
Data were recorded on different plant, leaf, flower, fruit and seed characteristics. Plant growth was determined by a formula : $\mathrm{H} \times \mathrm{N}$-S spread $\times \mathrm{E}-\mathrm{W}$ spread $\times 0.7$ a constant factor for citrus fruits, where $\mathrm{H}$ represents height, N-S represents north-south spread, and $\mathrm{E}-\mathrm{W}$ represents east-west spread and tree volume was measured by formula $1 / 6 \times \mathrm{H} \times$ $(2 r)^{2}$ Where, $\mathrm{H}=$ Height, $2 \mathrm{r}=($ East-West spread + North-South spread $) / 2$. Base girth one meter above the ground level was measured using a measuring tape. Ten leaves were selected randomly from each of three plants of each accession to study leaf shape and leaf apex. Leaf area was measured by leaf area meter (CI-202 area meter, CID, Inc, USA). The TSS was determined by hand refractometer (ATAGO NI Brix 0-32\%, Japan). External appearance, external colour and pulp colour of fruits of different accessions were recorded visually using a colour chart. The significance of difference between treatment means was evaluated by least significance difference (LSD) test.

\section{Statistical analysis}

The analysis of variances was performed by $\mathrm{F}$ variance test using the software program 'MSTAT'. Genotypic variance (GV) \& phenotypic variance (PV) was calculated using the formula, GV = MS-EMS $/ \mathrm{r}$ and PV = GV + EMS where, MS is mean square, EMS is error mean square and $r$ is replication. Genotypic co-efficient of variation $(\mathrm{GCV})$ \& phenotypic co-efficient of variation $(\mathrm{PCV})$ was calculated by the equation, $\mathrm{GCV}=(\mathrm{GSD} /$ mean $) \times 100$ and $\mathrm{PCV}=(\mathrm{PSD} /$ mean $) \times 100$, respectively where, GSD \& PSD are the genotypic \& phenotypic standard deviation, respectively. Spearman's rank correlation coefficients were calculated using the 'PLABSTAT' software version $2 \mathrm{~N}$ (Utzal, 2007) by using the formula of simple correlation coefficient, $\mathrm{r}_{\mathrm{xy}}=\mathrm{SP}(\mathrm{xy}) / \sqrt{\mathrm{SS}(\mathrm{x}) \cdot \mathrm{SS}(\mathrm{y})}$, where, $\mathrm{SP}(\mathrm{xy})$ is sum of products of $X \& Y$ and SS (x) \& SS (y) are sum of squares of $X$ and $Y$, respectively. Direct and indirect path coefficients were calculated by using the method as described by Lynch and Walsh (1998) using the software program 'BASICA'.

\section{RESULTS AND DISCUSSION}

\section{Plant characteristics}

Plant height varied significantly among the Jamir accessions ranging from $1.75 \mathrm{~m}$ (GJ16) to $6.20 \mathrm{~m}$ (CJ09) with the average value of $3.19 \mathrm{~m}$. Considerable differences were observed between genotypic $(1.46 \mathrm{~m})$ and phenotypic $(1.75 \mathrm{~m})$ variance as well as genotypic $(37.78 \%)$ and phenotypic $(39.21 \%)$ coefficient of variation indicating considerable environmental influence on this trait. Spread also varied significantly among the accessions ranging from $1.53 \mathrm{~m}$ CJ17 to $4.90 \mathrm{~m}$ CJ09 (North-South) and $1.54 \mathrm{~m} \mathrm{CJ13}$ to $4.87 \mathrm{~m} \mathrm{CJ09} \mathrm{(East-west).} \mathrm{Considerable} \mathrm{differences} \mathrm{were} \mathrm{observed} \mathrm{between} \mathrm{genotypic}$ $(1.39 \mathrm{~m}, 1.84 \mathrm{~m})$ and phenotypic $(1.59 \mathrm{~m}, 1.95 \mathrm{~m})$ variances as well as genotypic $(41.09 \%$, $47.79 \%)$ and phenotypic $(43.99 \%, 49.30 \%)$ coefficient of variation for north-south and eastwest direction, respectively indicating considerable environmental influence on this trait (Table 1). Base girth of Jamir ranged from $14.67 \mathrm{~cm}$ (CJ16) to $58.00 \mathrm{~cm}$ (CJ09). Considerable environmental influence was indicated by the difference between genotypic $(299.93 \mathrm{~cm})$ and variance $(314.86 \mathrm{~cm})$ and genotypic $(56.09 \%)$ and phenotypic $(57.51 \%)$ coefficient of 
variation. Number of primary branches/plant varied from 2.33 (CJ14) to 4.00 (CJ05). Considerable differences were found between genotypic (2.57) and phenotypic (3.20) variances as well as genotypic $(32.36 \%)$ and phenotypic $(36.54 \%)$ coefficient of variation. Plant growth varied from 4.05 (CJ16) to $102.76 \mathrm{~m}^{3}$ (CJ09) and high difference between genotypic (940.24\%) and phenotypic (968.55\%) variation as well as genotypic (113.15\%) and phenotypic $(114.84 \%)$ coefficient of variation indicated the existence of inherent variability among the accessions and has a high potentiality for selection. Tree volume ranged from $0.93 \mathrm{~m}^{3}$ (CJ17) to $24.64 \mathrm{~m}^{3}$ (CJ09) and the environmental influence was found by the little difference between genotypic $(54.054 \%)$ and phenotypic $(55.51 \%)$ variance as well as genotypic $(112.855 \%)$ and phenotypic $(114.36 \%)$ coefficient of variation. It was found that the plant of accessions CJ06, CJ09, CJ10, CJ11 and CJ12, were Umbrella shaped and of CJ04, CJ05, CJ15, CJ16, and CJ17 were open headed and of CJ13, CJ14, CJ18 and CJ19 were close headed (Data not shown). Spine length varied significantly from $8.20 \mathrm{~mm}$ (CJ17) to $25.33 \mathrm{~mm}$ (CJ15). The little difference between genotypic (30.77\%) and phenotypic $(30.834 \%)$ coefficient of variation indicated low environmental influences on this trait (Table 1).

\section{Leaf characteristics}

Leaf length ranged from 10.06 (CJ13) to 14.94 (CJ05) and moderate differences between genotypic $(1.58)$ and phenotypic $(2.93 \mathrm{~cm})$ variance as well as genotypic $(7.18 \%)$ and phenotypic $(13.77 \%)$ coefficient of variation indicated low environmental effect on this trait. Leaf width varied significantly from $3.72 \mathrm{~cm}$ CJ17 to $5.85 \mathrm{~cm}$ (CJ05). The environmental influence was considerable for this trait, which could be observed from the differences between phenotypic (15.86\%) and genotypic $(5.82 \%)$ coefficient of variation (Table 1). Lamina area ranged from 77.88 (CJ06) to $213.07 \mathrm{~cm}^{2}$ (CJ05). Considerable differences between genotypic $\left(1786.53 \mathrm{~cm}^{2}\right)$ and phenotypic $\left(2140.33 \mathrm{~cm}^{2}\right)$ variance as well as genotypic (31.69\%) and phenotypic (34.68\%) coefficient of variation indicated considerable environmental influence on this trait (Table 1).

Wing area varied significantly from 0.00 to $16.74 \mathrm{~cm}^{2}$ (CJ13). Very little differences were observed between genotypic $\left(3.03 \mathrm{~cm}^{2}\right)$ and phenotypic $(3.05 \mathrm{CM})$ variance and between phenotypic coefficient of variation $(137.82 \%)$ and genotypic coefficient of variation $(137.75 \%)$, which indicated the low environmental influence on this trait (Table 1). The highest Lamina: Wing ratio (80.52) was found in accession CJ10 followed by accession number CJ11 (62.30). Considerable differences were observed between genotypic (2506.96) and phenotypic (2508.71) variance as well as genotypic (227.28\%) and phenotypic $(227.369 \%)$ coefficient of variation indicating considerable environmental effect upon the expression of this character (Table 1). Leaf of accession number CJ04, CJ16 and CJ17 were ovate shaped and rest of the accessions had oblong leaves (Data not shown). Shape of petiole wing of the accessions CJ06, CJ09, CJ10, CJ11 and CJ12 was deltoid and that of CJ18 was cordiform. 
Table 1. Variability among 14 Jamir accession

\begin{tabular}{|c|c|c|c|c|c|}
\hline Characters & $\begin{array}{c}\text { Genotypic } \\
\text { variance } \\
(\mathrm{GV})\end{array}$ & $\begin{array}{c}\text { Pheotypic } \\
\text { variance } \\
(\mathrm{PV})\end{array}$ & $\begin{array}{l}\text { Genotypic } \\
\text { coefficient of } \\
\text { variation } \\
(\mathrm{GCV} \%)\end{array}$ & $\begin{array}{c}\text { Pheotypic } \\
\text { coefficient of } \\
\text { variation } \\
(\mathrm{PCV} \%)\end{array}$ & $\begin{array}{l}\text { Coefficient } \\
\text { of variation } \\
(\mathrm{CV} \%)\end{array}$ \\
\hline Plant height & 1.46 & 1.57 & 37.781 & 39.210 & 10.54 \\
\hline N-S spread & 1.39 & 1.59 & 41.089 & 43.99 & 15.77 \\
\hline E-W spread & 1.84 & 1.95 & 47.799 & 49.29 & 12.06 \\
\hline Base girth(cm) & 299.93 & 314.86 & 56.091 & 57.51 & 12.52 \\
\hline $\begin{array}{l}\text { No. of primary } \\
\text { branches/plant }\end{array}$ & 2.57 & 3.20 & 32.36 & 36.54 & 28.90 \\
\hline Plant growth $\left(\mathrm{m}^{3}\right)$ & 940.24 & 968.55 & 113.153 & 114.84 & 19.64 \\
\hline Tree volume $\left(\mathrm{m}^{3}\right)$ & 54.05 & 55.51 & 112.845 & 114.35 & 18.51 \\
\hline Spine length & 17.50 & 17.57 & 30.770 & 30.83 & 1.95 \\
\hline Leaf length & 1.58 & 2.93 & 13.177 & 13.76 & 4.00 \\
\hline Leaf width & 0.38 & 0.56 & 5.821 & 15.86 & 9.08 \\
\hline Lamina area & 1786.53 & 2140.33 & 31.686 & 34.68 & 14.10 \\
\hline Wing area & 3.03 & 3.05 & 137.754 & 137.82 & 4.01 \\
\hline Lamina : Wing ratio & 2506.96 & 2508.71 & 227.279 & 227.36 & 5.99 \\
\hline Length flower bud & 0.164 & 0.183 & 15.751 & 16.639 & 5.33 \\
\hline Length of pedicel & 0.047 & 0.053 & 29.232 & 30.943 & 10.62 \\
\hline Length of petal & 0.290 & 0.296 & 23.222 & 23.461 & 3.36 \\
\hline Width of petal & 0.023 & 0.028 & 20.775 & 22.922 & 9.51 \\
\hline No. of stamen/flower & 21.314 & 22.018 & 12.971 & 13.183 & 2.36 \\
\hline Fruit diameter & 83.736 & 91.676 & 31.161 & 31.489 & 4.58 \\
\hline Fruit weight & 293595.301 & 294782.074 & 72.195 & 72.342 & 4.59 \\
\hline Rind thickness & 0.698 & 0.7016 & 62.817 & 62.979 & 4.19 \\
\hline $\begin{array}{l}\text { Number of segment } \\
\text { per fruit }\end{array}$ & 1.644 & 2.249 & 10.365 & 12.123 & 6.30 \\
\hline Length of segment & 3.141 & 3.155 & 22.829 & 22.881 & 1.54 \\
\hline Pulp weight & 60866.004 & 61205.24 & 62.161 & 62.334 & 4.64 \\
\hline$\%$ Fruit set & 12.382 & 17.766 & 11.70 & 14.019 & 7.72 \\
\hline TSS & 0.114 & 0.122 & 2.987 & 3.081 & 0.81 \\
\hline No. of seed per fruit & 756.004 & 746.157 & 43.644 & 43.359 & 4.53 \\
\hline Seed length & 0.044 & 0.051 & 16.957 & 18.185 & 6.51 \\
\hline
\end{tabular}

\section{Flower characteristics}

Length of pedicel ranged from 0.5 (CJ05) to $1.10 \mathrm{~cm}$ (CJ04) with the mean value of $0.74 \mathrm{~cm}$. The phenotypic variance $(0.053 \mathrm{~cm})$ was slightly higher than genotypic variance $(0.047 \mathrm{~cm})$ indicating negligible environmental influence on this trait (Table 1). Length of flower bud 
ranged from 1.40 (CJ05) to $3.50 \mathrm{~cm}$ (CJ04). The little difference between phenotypic $(0.183 \mathrm{~cm})$ and genotypic $(0.164 \mathrm{~cm})$ variance and genotypic $(15.75 \%)$ and phenotypic $(16.64 \%)$ coefficient of variation indicated considerable environmental effect on this trait (Table 1). Length of petal ranged from 1.50 (CJ09) to $3.17 \mathrm{~cm}$ (CJ11). The phenotypic variance $(0.296 \mathrm{~cm})$ was slightly higher than genotypic variance $(0.290 \mathrm{~cm})$ indicating negligible environmental influence on length of petal. Width of petal ranged from $0.53 \mathrm{~cm}$ (CJ09) to $2.50 \mathrm{~cm}$ (CJ12). Little differences between genotypic $(0.023 \mathrm{~cm})$ and phenotypic $(0.028 \mathrm{~cm})$ variance and genotypic $(21.775 \%)$ and phenotypic $(22.922 \%)$ coefficient of variation as well indicated low environmental influence on this trait (Table 1). Number of stamen per flower ranged from 25.00 (CJ09) to 41.33 (CJ04). The phenotypic variance (22.018) was slightly higher than genotypic variance (21.314) and the phenotypic coefficient of variation $(13.183 \%)$ was also slightly higher than the genotypic coefficient of variation $(12.971 \%)$ indicating considerable environmental influence on this trait (Table 1). Percent fruit set ranged from 25.40 (CJ11) to $36.67 \%$ (CJ12). Relatively wide variation was observed between phenotypic and genotypic co-efficient of variation $(14.019 \%$ and $7.72 \%$, respectively) as well as phenotypic and genotypic variance (17.776 and 12.382 , respectively) indicating much environmental influence upon this trait (Table 1). The character is very important for varietal selection.

\section{Fruit characteristics}

Fruit weight varied significantly from $125.00 \mathrm{~g}$ (CJ06) to $1753.33 \mathrm{~g}$ (CJ11). Little differences between genotypic (293595.301g) and phenotypic (294782.074g) variance and also genotypic $(72.195 \%)$ and phenotypic $(72.342 \%)$ coefficient of variation indicated low environmental influence on this trait (Table 1). Fruit diameter ranged from 19.00 (CJ06) to $46.00 \mathrm{~cm}$ (CJ11). Little differences observed between genotypic $(31.161 \%)$ and phenotypic $(31.489 \%)$ coefficient of variation indicated low environmental influence on this trait (Table 1). Rind thickness ranged from 0.43 (CJ06) to $2.75 \mathrm{~cm}$ (CJ11). Little differences between genotypic $(62.817 \%)$ and phenotypic $(62.979 \%)$ coefficient of variation indicated low environmental influence on this trait. Number of segments/fruit varied significantly 10.67 (CJ15) to 15.33 (CJ09). The differences between genotypic and phenotypic variance (1.644 and 2.249, respectively) as well as genotypic and phenotypic co-efficient of variation $(10.365 \%$ and $12.123 \%$, respectively) indicated moderate environmental influence on this trait (Table 1). Length of segment ranged from $5.50 \mathrm{~cm}(\mathrm{CJ} 15)$ to $9.70 \mathrm{~cm}$ (CJ09). Little differences between genotypic $(3.141 \mathrm{~cm})$ and phenotypic $(3.155 \mathrm{~cm})$ variances as well as genotypic $(22.829 \%)$ and phenotypic $(22.881 \%)$ coefficient of variation indicated low environmental influence on this trait (Table 1). Pulp weight ranged from $81.00 \mathrm{~g}$ (CJ15) to $746.00 \mathrm{~g}$ (CJ09). Total soluble solids (TSS) percentage significantly varied from $11.03 \%$ (CJ04) to $12.20 \%$ (CJ12) with the mean value of $11.34 \%$. Little differences between genotypic $(0.114 \%)$ and phenotypic $(0.122 \%)$ variance as well as genotypic $(2.987 \%)$ and phenotypic $(3.081 \%)$ coefficient of variation indicated moderate environmental influence on this trait (Table 1). Fruit size of accession CJ10, CJ11 and CJ12 were large, accession CJ04 and CJ05 were medium and accession CJ06, CJ09, CJ15 and CJ19 were small. Seed length differed from $0.80 \mathrm{~cm}(\mathrm{CJ} 15)$ to $1.53 \mathrm{~cm}$ (CJ12). The phenotypic $(0.051 \mathrm{~cm})$ and genotypic variance $(0.044 \mathrm{~cm})$ indicated moderate 
environmental influence on this trait (Table 1) which was supported by the narrow differences between genotypic (16.597\%) and phenotypic $(18.185 \%)$ coefficient of variation. Number of seeds/fruit ranged from 14.00 (CJ09) to 105.00 (CJ11). Little differences were observed between genotypic and phenotypic coefficient of variation $(43.644 \%$ and $43.359 \%$, respectively) indicating low environmental effects on this trait (Table 1).

\section{Correlation coefficient}

Fruit diameter showed positive genotypic and phenotypic association with all traits except for percent fruit set $(\mathrm{gr}=-0.074, \mathrm{pr}=-0.300)$ which indicates that with the increase of fruit diameter, \% fruit set will be decreased (Table 2 and 3). The trait showed highly significant positive phenotypic association with rind thickness and fruit weight ( $\mathrm{pr}=0.867$ for both the traits). Rind thickness showed positive genotypic and phenotypic association with all the traits except negative phenotypic association with no. of segment $(-0.014)$ and fruit weight $(0.291)$. The trait showed highly significant positive phenotypic association with fruit weight (0.900). The result reveals that with the increase of length of segment, no. of seed/fruit, length of seed/fruit, fruit weight will be increased. Number of segment exhibited negative genotypic and phenotypic association with number of seed $/$ fruit $(\mathrm{pr}=-0.433$, gr $=-0.227$, percent fruit set $(\mathrm{pr}=-0.467$, gr $=-0.115)$. The trait showed positive association with all other traits and among these associations highly significant phenotypic association was found with seed length $(\mathrm{pr}=0.667)$.

Table 2. Genotypic correlations between yield and yield contributing characters of 9 Jamir accession

\begin{tabular}{l|c|c|c|c|c|c|c}
\hline \multicolumn{1}{c|}{ Traits } & $\begin{array}{c}\text { Rind } \\
\text { thickness } \\
(\mathrm{cm})\end{array}$ & $\begin{array}{c}\text { No. of } \\
\text { segment }\end{array}$ & $\begin{array}{c}\text { Length of } \\
\text { segment } \\
(\mathrm{cm})\end{array}$ & $\begin{array}{c}\text { No. of } \\
\text { seed } \\
\text { /fruit }\end{array}$ & $\begin{array}{c}\text { Length } \\
\text { of seed } \\
(\mathrm{cm})\end{array}$ & $\begin{array}{c}\text { \% fruit } \\
\text { set }\end{array}$ & $\begin{array}{c}\text { Fruit } \\
\text { weight }\end{array}$ \\
\hline Fruit diameter $(\mathrm{cm})$ & 0.305 & 0.015 & 0.237 & 0.138 & 0.153 & -0.074 & 0.285 \\
Rind thickness (cm) & & -0.014 & 0.214 & 0.169 & 0.148 & -0.060 & 0.291 \\
Number of segment & & & 0.172 & -0.227 & 0.174 & -0.115 & 0.089 \\
Length of segment (cm) & & & & -0.073 & 0.262 & -0.0015 & 0.284 \\
No. of seed/fruit & & & & & -0.136 & 0.036 & 0.075 \\
Length of seed (cm) & & & & & & 0.278 & 0.175 \\
\% fruit set & & & & & & -0.079 \\
\hline
\end{tabular}

Length of segment had negative genotypic and phenotypic association with number of seed $/$ fruit $(\mathrm{pr}=-0.433, \mathrm{gr}=-0.073)$, percent fruit set $(\mathrm{pr}=-0.183$, gr $=-0.0015)$. It showed significant and positive phenotypic association with fruit weight $(\mathrm{pr}=0.783)$. This indicated that with the increase of length of segment, fruit weight will also be increased. No. of seed/fruit had negative correlation with length of seed $(\mathrm{pr}=-0.517 \mathrm{gp}=-0.136)$ and only negative phenotypic association with \%fruit set. Positive phenotypic and genotypic association was found with the fruit weight $(\mathrm{pr}=0.150$, gr $=0.075)$ which indicated that fruit weight will be increased with the increase of no. of seed/fruit. Seed 
length had a positive phenotypic and genotypic relation with \%fruit set $(\mathrm{pr}=0.083$, gr $=$ $0.073)$ and fruit weight $(\mathrm{pr}=0.175, \mathrm{gr}=0.550)$. Percent fruit set had negative association with fruit weight both phenotypicaily and genotypically $(\mathrm{pr}=-0.300$, gr $=-0.079)$ indicating that \% fruit set will decrease with the increase of fruit weight (Table $2 \& 3$ ).

Table 3. Phenotypic correlations between yield and yield contributing characters of 9 Jamir accessions

\begin{tabular}{l|c|c|c|c|c|c|c}
\hline \multicolumn{1}{c|}{ Traits } & $\begin{array}{c}\text { Rind } \\
\text { thickness } \\
(\mathrm{cm})\end{array}$ & $\begin{array}{c}\text { No. of } \\
\text { segment }\end{array}$ & $\begin{array}{c}\text { Length of } \\
\text { segment } \\
(\mathrm{cm})\end{array}$ & $\begin{array}{c}\text { No. of } \\
\text { seed } \\
\text { fruit }\end{array}$ & $\begin{array}{c}\text { Length } \\
\text { of seed } \\
(\mathrm{cm})\end{array}$ & $\begin{array}{c}\text { \%fruit } \\
\text { set }\end{array}$ & $\begin{array}{c}\text { Fruit } \\
\text { weight }\end{array}$ \\
\hline Fruit diameter $(\mathrm{cm})$ & $0.867^{* *}$ & 0.400 & 0.517 & 0.317 & 0.450 & -0.300 & $0.867^{* *}$ \\
Rind thickness $(\mathrm{cm})$ & & 0.450 & 0.617 & 0.233 & 0.567 & 0.300 & $0.900^{* *}$ \\
Number of segment & & & 0.617 & -0.433 & $0.667^{*}$ & -0.467 & 0.467 \\
Length of segment $(\mathrm{cm})$ & & & & -0.433 & $0.817^{* *}$ & -0.183 & $0.783^{*}$ \\
No. of seed/fruit & & & & & -0.517 & -0.117 & 0.150 \\
Length of seed (cm) & & & & & & 0.083 & 0.550 \\
\% fruit set & & & & & & -0.300 \\
\hline
\end{tabular}

* ** indicates significant at $5 \%$ \& $1 \%$ level of probability, respectively, $\mathrm{df}=\mathrm{N}-2$

\section{Path coefficient analysis}

The genotypic (g) and phenotypic (p) direct and indirect effects of different characters on yield/plant are presented in Table 4 and 5. Fruit diameter had positive genotypic direct effect $(g=0.1504)$ and phenotypic direct effect $(p=0.2799)$ on fruit weight. Negligible genotypic indirect positive effect to fruit weight was contributed via rind thickness (0.0466), number of segment (0.0031), length of segment (0.0361), number of seed/fruit (0.0211) and length of seed (0.0226). The trait also showed positive phenotypic indirect effect to all traits except percent fruit set $(-0.0839)$. Rind thickness showed positive direct genotypic $(g=0.1726)$ and phenotypic $(p=0.4726)$ effect on fruit weight. It had positive genotypic indirect effect with all characters except with no. of segment $(-0.0017)$ and \% fruit set $(-0.0103)$ and it had negative phenotypic indirect effect only with $\%$ fruit set (0.1246). Number of segment had direct positive effect $(p=0.1903, g=0.0458)$ on fruit weight. It showed indirect positive effect on fruit weight via genotypic fruit diameter, length of segment, seed length, \%fruit set and phenotypic fruit diameter, rind thickness, length of segment. It showed indirect negative effect on fruit weight via genotypic and phenotypic no. of seed/fruit, genotypic rind thickness and phenotypic seed length and \% fruit set.

Length of segment showed direct genotypic and phenotypic effect $(g=0.1754, p=0.7916)$ on fruit weight. Length of segment had indirect positive effect on fruit weight via genotypic and phenotypic fruit diameter, rind thickness and number of segment, genotypic no. of seed/fruit and \%fruit set, whereas negative indirect effect was found via genotypic and phenotypic no. of seed per fruit, and phenotypic seed length and \% fruit set. No. of seed/fruit had direct positive genotypic and phenotypic effect on fruit weight 
( $g=0.0717, p=0.1319$ and positive indirect effect of no. of seed/fruit on fruit weight was contributed via genotypic and phenotypic fruit diameter and rind thickness and phenotypic seed length where as negative indirect effect was found on genotypic and phenotypic number of segment, length of segment and \% fruit set and genotypic seed length. Seed length showed direct positive genotypic $(g=0.1128)$ and negative phenotypic $(p=-0.5367)$ effect on fruit weight. This trait had indirect positive effect on fruit weight via genotypic and phenotypic fruit diameter, rind thickness, number of segment and length of segment and phenotypic \%fruit set. It also had indirect negative genotypic and phenotypic effect on fruit weight via no. of seed per fruit and genotypic $\%$ fruit set. Percent fruit set had considerable direct negative genotypic effect $(g=-0.0877)$ and phenotypic positive effect $(\mathrm{p}=0.1993)$ on fruit weight (Table 4 and 5$)$. It exhibited low indirect negative effect on fruit weight via fruit diameter, rind thickness, and number of segment and length of segment, phenotypic no. of seed per fruit and seed length. It has also indirect positive effect on fruit weight via genotypic no. of seed per fruit and seed length. Thus, fruit diameter, rind thickness, number of segment and length of segment were the potential yield contributing character to the fruit weight.

Table 4. Genotypic path-coefficient analysis for yield components towards fruit weight in Jamir (Residual effect: 0.666. Underline and bold figures indicate the direct effects)

\begin{tabular}{l|c|c|c|c|c|c|c|c}
\hline \multicolumn{1}{c|}{ Traits } & $\begin{array}{c}\text { Fruit } \\
\text { diameter } \\
(\mathrm{cm})\end{array}$ & $\begin{array}{c}\text { Rind } \\
\text { thickness } \\
(\mathrm{cm})\end{array}$ & $\begin{array}{c}\text { No. of } \\
\text { segment }\end{array}$ & $\begin{array}{c}\text { Length of } \\
\text { segment } \\
(\mathrm{cm})\end{array}$ & $\begin{array}{c}\text { No. of } \\
\text { seed } \\
\text { /fruit }\end{array}$ & $\begin{array}{c}\text { Length } \\
\text { of seed } \\
(\mathrm{cm})\end{array}$ & $\begin{array}{c}\text { \%fruit } \\
\text { set }\end{array}$ & $\begin{array}{c}\text { Fruit } \\
\text { weight } \\
(\mathrm{g})\end{array}$ \\
\hline Fruit diameter $(\mathrm{cm})$ & $\mathbf{0 . 1 5 0 4}$ & 0.0466 & 0.0031 & 0.0361 & 0.0211 & 0.0226 & -0.0105 & 0.285 \\
Rind thickness (cm) & 0.0535 & $\mathbf{0 . 1 7 2 6}$ & -0.0017 & 0.0363 & 0.0293 & 0.0259 & -0.0103 & 0.291 \\
No. of segment & 0.0009 & -0.0005 & $\underline{\mathbf{0 . 0 4 5 8}}$ & 0.0077 & -0.0105 & 0.0077 & -0.0055 & 0.089 \\
Length of segment (cm) & 0.0421 & 0.0368 & 0.0298 & $\underline{\mathbf{0 . 1 7 5 4}}$ & -0.0123 & 0.0456 & -0.0004 & 0.284 \\
No. of seed/fruit & 0.0101 & 0.0122 & -0.0164 & -0.0050 & $\underline{\mathbf{0 . 0 7 1 6 8}}$ & -0.0100 & 0.0029 & 0.075 \\
Length of seed (cm) & 0.0169 & 0.0169 & 0.0192 & 0.0293 & -0.0158 & $\underline{\mathbf{0 . 1 1 2 8}}$ & 0.0316 & 0.175 \\
\% fruit set & 0.0061 & 0.0053 & 0.0105 & 0.0002 & -0.0035 & -0.0245 & $\underline{\mathbf{- 0 . 0 8 7 7}}$ & -0.079 \\
\hline
\end{tabular}

Table 5. Phenotypic path-coefficient analysis for yield components towards fruit weight in Jamir (Residual effect: 0.666.Underline and bold figures indicate the direct effects)

\begin{tabular}{l|c|c|c|c|c|c|c|c}
\hline \multicolumn{1}{c|}{ Traits } & $\begin{array}{c}\text { Fruit } \\
\text { diameter } \\
(\mathrm{cm})\end{array}$ & $\begin{array}{c}\text { Rind } \\
\text { thickness } \\
(\mathrm{cm})\end{array}$ & $\begin{array}{c}\text { No. of } \\
\text { segment }\end{array}$ & $\begin{array}{c}\text { Length of } \\
\text { segment } \\
(\mathrm{cm})\end{array}$ & $\begin{array}{c}\text { No. of } \\
\text { seed } \\
/ \text { fruit }\end{array}$ & $\begin{array}{c}\text { Length } \\
\text { of seed } \\
(\mathrm{cm})\end{array}$ & $\begin{array}{c}\text { \%Fruit } \\
\text { set }\end{array}$ & $\begin{array}{c}\text { Fruit } \\
\text { weight } \\
(\mathrm{g})\end{array}$ \\
\hline Fruit diameter $(\mathrm{cm})$ & $\underline{\mathbf{0 . 2 7 9 9}}$ & 0.2436 & 0.1119 & 0.1456 & 0.08959 & 0.1260 & -0.0839 & 0.867 \\
Rind thickness (cm) & 0.3614 & $\underline{\mathbf{0 . 4 1 5 4}}$ & 0.1869 & 0.2575 & 0.0553 & 0.2368 & -0.1246 & 0.900 \\
No. of segment & 0.0611 & 0.0856 & $\mathbf{0 . 1 9 0 3}$ & 0.1179 & -0.0818 & 0.1275 & -0.0894 & 0.467 \\
Length of segment $(\mathrm{cm})$ & 0.4116 & 0.4907 & 0.4908 & $\underline{\mathbf{0 . 7 9 1 6}}$ & -0.3403 & 0.6491 & -0.0142 & 0.738 \\
No. of seed per fruit & 0.0422 & 0.0303 & -0.0567 & -0.0567 & $\underline{\mathbf{0 . 1 3 1 9}}$ & -0.0686 & -0.0158 & 0.150 \\
Length of seed (cm) & -0.2415 & -0.3059 & -0.3595 & -0.4401 & 0.2790 & $\underline{\mathbf{- 0 . 5 3 6 7}}$ & -0.0429 & 0.550 \\
\%fruit set & 0.2436 & --0.0598 & -0.0937 & -0.0359 & -0.0239 & 0.0159 & $\underline{\mathbf{0 . 1 9 9 3}}$ & -0.300 \\
\hline
\end{tabular}


From the above study, higher variation was observed for different characters among the genotypes that offered better scope of selecting distant parents for future breeding programs. Selection of superior genotypes from the collected germplasm will be helpful to increase production through selective breeding program which in turn could improve livelihood of farmer and overall socio-economic condition of the country.

\section{REFERENCES}

Ahmed, F., Zareen, M., Khan, R., Banu, C. P., Haq, M. N. and Jackson, A. A. 1998. Dietary pattern, nutrient intake and growth of adolescent school girls in urban Bangladesh. Public Health Nature, (2): 83-92.

Dewey, D. K. and Lu, K. H. 1989. A correlation and path coefficient analysis of components of crested wheat grass and production. Agron. J., 51: 515-518.

FAO, 2003a. Citrus Fruit. Medium-term prospects for agricultural commodities Projections to the Year 2010. Series title: FAO Commodities and Trade Technical Papers-1, Food and Agriculture Organization of the United Nations, Rome.

FAO. 2003b. Selected indicators of food and agriculture development in Asia-Pacific region 1999-2002. Food and Agriculture Organization of the United Nations,

Hels, O., Kidmose, U., Larsen, T., Hassan, N., Tetens, I. and Thilsted, S. H. 2003. Estimated nutrient intakes and adequacies in Bangladesh change when newer values for vitamin A, iron and calcium in commonly consumed foods are applied. Int. J. Food Sci. Nutr., 54(6): 457-465.

Khan, M. R. and Ahmed, F. 2005. Physical status, nutrient intake and dietary pattern of adolescent female factory workers in urban Bangladesh. Asia. Pac. J. Clin. Nutr., 14(1): 19-26.

Lee, R. and Leader, R. 2004. USDA-ARS National clonal germplasm repository for Citrus \& Dates in Riverside, California- Annual Report. p. 2.

Lynch, M., Walsh, B. 1998. Genetics and Analysis of Quantitative Traits. Sinauer associates Inc. Sunderland, Mossachusetts, pp. 823-831.

Nielsen, H. 2000. Food and nutrient intake among females in rural Bangladesh. Master in Human Nutrition Dissertation, Research Department of Human Nutrition, The Royal Veterinary and Agricultural University, Copenhagen, Denmark.

Spreen, T. H. 2001. Projections of World Production and Consumption of Citrus to 2010. Proc. Chinai FAO Citrus Symp., 14-17 May 2001. Beijing.

Utzzal H. F. 2007. PLABSTAT (Version 2N). A Computer Program for the Computation of Variances and Covariances. Institute of Plant Breeding, Seed Science and Population Genetics. University of Hohenluim, Stuttgart, Germany. (http://www. Un-hohenluim. de/ipsp www/soft. Html citid 25 August 2007). 